\title{
Endothelial Progenitor Cells: Novel Biological Marker for Risk Stratification in Arterial Hypertension?
}

\author{
Alexander E Berezin* \\ Internal Medicine Department, Ukraine \\ *Corresponding author: Alexander E Berezin, Senior Consultant of Therapeutic Unit, Internal Medicine Department, Ukraine
}

\begin{tabular}{|c|c|}
\hline ARTICLE INFO & ABSTRACT \\
\hline $\begin{array}{l}\text { Received: 㗀 January 31, } 2019 \\
\text { Published: 幽 February 13, } 2019\end{array}$ & $\begin{array}{l}\text { Endothelial progenitor cells (EPC) were found as biological marker of endothelial dy- } \\
\text { scfunction in several cardiovascular diseases including hypertension. Recent pre-clinical } \\
\text { and clinical studies have revealed that reduced number and weak function of circulat- }\end{array}$ \\
\hline $\begin{array}{l}\text { Citation: Alexander E Berezin. En- } \\
\text { dothelial Progenitor Cells: Novel Bio- } \\
\text { logical Marker for Risk Stratification } \\
\text { in Arterial Hypertension?. Biomed } \\
\text { J Sci \& Tech Res 14(3)-2019. BJSTR. } \\
\text { MS.ID.002566. }\end{array}$ & $\begin{array}{l}\text { ing EPCs may proceed to arterial hypertension and associate with severity of the disease. } \\
\text { However, there are serious controversies in understanding causative role of EPC dysfunc- } \\
\text { tion in nature evolution of arterial hypertension. The Editorial is depicted the phenome- } \\
\text { non of EPC dysfunction in arterial hypertension as a independent predictive biomarker } \\
\text { of the disease. It has been suggesting that hypertensive patients present impaired repair } \\
\text { capacity EPCs compared with healthy volunteers, but perhaps EPCs dysfunction is not } \\
\text { cause of hypertension, while it may contribute to target organ damage manifestation and } \\
\text { appearing CV complications. }\end{array}$ \\
\hline
\end{tabular}

Keywords: Hypertension; Cardiovascular Risk; Endothelial Progenitor Cells; Prognosis

\section{Introduction}

Endothelial progenitor cells (EPC) are defined as CD34(+) precursors of mature endothelial cells originated from pre-endothelial resident cells or having mononuclear origin [1]. EPCs are involved in maintaining vascular integrity, endothelial function, vascular repair and angiogenesis [2]. There is a large body of evidence regarding the pivotal role of EPCs in developing cardiovascular (CV) diseases and CV events [3-6]. For instance, nature evolution of vast range of CV diseases were associated with deficiency of circulating number of EPCs as well as weak function of endothelial precursors including mobbing, proliferation, differentiation and survival, which were incorporated into term EPC dysfunction [7]. In patients with pre-hypertension and hypertension lowered number and declined function of EPCs were identified and EPC dysfunction appeared to be a biomarker of endothelial dysfunction and arterial stiffness [8]. However, there are serious controversies in understanding whether EPCs dysfunction is causative factor for arterial hypertension or it appears to be just whiteness of nature evolution of endothelial dysfunction. Indeed, impaired endothelial repair capacity of early EPCs was found in pre-hypertensive in significantly relation to conventional CV risk factors $[9,10]$. However, an accelerating senescence of early EPCs was being an attribute of aging, some CV risk factors (smoking, abdominal obesity, insulin resistance, dyslipidemia), co-existing metabolic conditions including diabetes mellitus, hyperuricemia, hyperthyroidism, atherosclerosis [11].

In fact, number and function of pro-angiogenic EPCs with immune phenotypes CD34+CD133+, CD34+CD133+VEGFR2+, and CD34+CD133+VEGFR2+Tei2+ are reduced in hypertensive patients and in hypertensive disorders of pregnancy and strong correlate to severity of endothelial dysfunction. Nevertheless, clear characterization of dysfunctional phenotype of circulating EPCs in pre-hypertensive patients includes shaping of colonies and ability to trans-differentiation into mature endothelial cells and smooth muscle vascular cells were found in close relation to co-morbidity conditions, while similar association was not confirmed in arterial hypertension patients $[12,13]$. Moreover, there was no evidence between impaired vascular integrity evaluated as EPCs dysfunction and excess CV morbidity and mortality in patients with pre-hypertension, but for hypertensive patients including gestational hypertensive female the evidence was received $[14,15]$. The exact molecular mechanisms, which lead to EPC dysfunction in pre-hy- 
pertensive and hypertensive patients, are not fully clear. Because EPCs are able to enhance neovascularization and support vascular function through the JAK2/STAT3 signaling pathways, wide spectrum factors contributing to expression on the surface of EPC appropriate $\mathrm{Tie} 2+$ receptors could be embedded in this interacting.

Yet, epigenetic impact on the Lnk gene in EPCs, which are crucial for proliferation, migration, and tubule-like formation and for angiogenesis overall, is considered a core element for shaping incompetence of EPCs. There are wide ranges of stimuli that are candidates for co-regulators of epigenetic influences and receptor-targeting effectors result in both decreasing number of EPCs in peripheral blood and weak their function, i.e. inflammatory cytokines, increased fasting glucose, hyperinsulinemia, components of oxidative stress such as oxidized low-density protein cholesterol, galectines, free radicals, as well as growth factors (growth factor-bets), catecholamines, and hormones (renin, angiotensin-II, aldosterone, endothelin-1) $[4,7,10]$. Unfortunately, all these findings do not explain why some patients without CV risk factors demonstrate EPC dysfunction before hypertension manifestation. For instance, in early pregnancy female at risk of preeclampsia and with established preeclampsia the number of circulating pro-angiogenic EPCs was lower in comparison to pregnancy female in the absence of preeclampsia risk [16]. Additionally, EPC colony formation, as well as differentiation and migration abilities were also impaired in the gestational hypertensive female [17]. It has been speculated that vascular health in early pregnancy could be altered in women with aberrant numbers of EPCs with pro-angiogenic immune phenotypes (CD34+CD133+VEGFR+ or CD34+CD133+VEGFR+Tie2+) and might represent significant $\mathrm{CV}$ maladaptation contributing to an increased risk of preeclampsia. The majority of data received by several investigators supported a hypothesis that EPCs dysfunction reflects an endothelial alteration that accompanies arterial hypertension and that the extent of endothelial damage does not appear to be associated with the severity of the disease [18].

Additionally, in pulmonary hypertension colony forming ability of EPCs was rather associated with right ventricular (RV) remodeling and RV dilation than pulmonary vascular obstruction and disease severity [19]. However, EPC dysfunction is novel biological marker of endothelial dysfunction and vascular reparation in hypertension with predictive value requires to be investigated in large clinical trials. In conclusion, hypertensive patients present greater apoptosis and impaired repair capacity EPCs that they were found in healthy individuals, but perhaps EPCs dysfunction is not cause of hypertension, while impaired EPC function may contribute to target organ damage manifestation and appearing CV complications.

\section{References}

1. Asahara T, Murohara T, Sullivan A, Silver M, Van der Zee R, et al. (1997) Isolation of putative progenitor endothelial cells for angiogenesis. Science 275(5302): 964-967.

2. Asahara T, Kawamoto A, Masuda H (2011) Concise review: circulating endothelial progenitor cells for vascular medicine. Stem Cells 29(11): 1650-1655.
3. Shimizu Y, Sato S, Koyamatsu J, Yamanashi H, Nagayoshi M, et al. (2015) Circulating CD34-positive cells, glomerular filtration rate and triglycerides in relation to hypertension. Atherosclerosis 243(1): 71-76.

4. Berezin AE, Kremzer AA (2014) Relationship between circulating endothelial progenitor cells and insulin resistance in non-diabetic patients with ischemic chronic heart failure. Diabetes \& Metabolic Syndrome: Clinical Research \& Reviews 8(3): 138-144.

5. Shimizu Y, Sato S, Koyamatsu J, Yamanashi H, Nagayoshi M, et al. (2018) Hepatocyte growth factor and carotid intima-media thickness in relation to circulating CD34-positive cell levels. Environ Health Prev Med 23(1): 16.

6. Berezin AE, Kremzer AA (2013) Analysis of various subsets of circulating mononuclear cells in asymptomatic coronary artery disease. Journal of clinical medicine 2(3): 32-44.

7. Berezin AE (2018) The endothelial progenitor cell dysfunction in hypertension: the diagnostic and predictive values. Vessel Plus 2: 22.

8. Cheng S, Wang N, Larson MG, Palmisano JN, Mitchell GF, et al. (2012) Circulating angiogenic cell populations, vascular function, and arterial stiffness. Atherosclerosis 220(1): 145-150.

9. Berezin AE, Kremzer AA, Samura TA, Berezina TA, Martovitskaya YV (2014) Serum uric acid predicts declining of circulating proangiogenic mononuclear progenitor cells in chronic heart failure patients. J Cardiovasc Thorac Res 6(3): 153-162.

10. Hoenig MR, Bianchi C, Sellke FW (2008) Hypoxia inducible factor-1 alpha, endothelial progenitor cells, monocytes, cardiovascular risk, wound healing, cobalt and hydralazine: a unifying hypothesis. Curr Drug Targets 9(5): 422-435.

11. Giannotti G, Doerries C, Mocharla PS, Mueller MF, Bahlmann FH, et al. (2010) Impaired endothelial repair capacity of early endothelial progenitor cells in prehypertension: relation to endothelial dysfunction. Hypertension 55(6): 1389-1397.

12. Chen L, Ding ML, Wu F, He W, Li J, et al.(2016) Impaired Endothelial Repair Capacity of Early Endothelial Progenitor Cells in Hypertensive Patients With Primary Hyperaldosteronemia: Role of 5,6,7,8-Tetrahydrobiopterin Oxidation and Endothelial Nitric Oxide Synthase Uncoupling. Hypertension 67(2): 430-439.

13. Geft D, Schwartzenberg S, George J (2008) Circulating endothelial progenitor cells in cardiovascular disorders. Expert Rev Cardiovasc Ther 6(8): 1115-1121.

14. Berezin AE (2015) Biological markers of cardiovascular diseases. Part 4. Diagnostic and prognostic value of biological markers at risk stratification among patients with heart failure. In Berezin AE (Eds.) Lambert Academic Publishing GmbH, Moskow, pp. 329.

15. Shantsila E, Watson T, Lip GY (2007) Endothelial progenitor cells in cardiovascular disorders. J Am Coll Cardiol 49(7): 741-752.

16. Von Versen Höynck F, Narasimhan P, Selamet Tierney ES, Martinez N, Conrad KP, et al. (2019) Absent or Excessive Corpus Luteum Number Is Associated With Altered Maternal Vascular Health in Early Pregnancy. Hypertension. 2019: Hypertensionaha.

17. Wang Y, Liu C, He X, Li Y, Zou Y (2019) Effects of Metoprolol, Methyldopa, and Nifedipine on Endothelial Progenitor Cells in Patients with Gestational Hypertension and Preeclampsia. Clin Exp Pharmacol Physiol.

18. Mudyanadzo TA (2018) Endothelial Progenitor Cells and Cardiovascular Correlates. Cureus 10(9): e3342.

19. Smits J, Tasev D, Andersen S, Szulcek R, Botros L, et al. (2018) Blood Outgrowth and Proliferation of Endothelial Colony Forming Cells are Related to Markers of Disease Severity in Patients with Pulmonary Arterial Hypertension. Int J Mol Sci 19(12): E3763. 


\section{ISSN: 2574-1241}

DOI: 10.26717.BJSTR.2019.14.002566

Alexander E Berezin. Biomed J Sci \& Tech Res

(C) (i) This work is licensed under Creative

Submission Link: https://biomedres.us/submit-manuscript.php

$\begin{array}{ll}\text { BIOMEDICAL } & \text { Assets of Publishing with us } \\ \text { RESEARCHES } & \text { - Global archiving of articles } \\ \text { - Immediate, unrestricted online access } & \text { - Rigorous Peer Review Process } \\ & \text { - Authors Retain Copyrights }\end{array}$

